\title{
Advanced Peritoneal Malignant Mesothelioma
}

National Cancer Institute

\section{Source}

National Cancer Institute. Advanced Peritoneal Malignant Mesothelioma. NCI Thesaurus.

Code C8704.

A malignant mesothelioma that arises from the peritoneum and has spread in the abdominal cavity. It may result in bowel obstruction. 